\title{
Prolonged ST Segment by ECG Finding
}

National Cancer Institute

\section{Source}

National Cancer Institute. Prolonged ST Segment by ECG Finding. NCI Thesaurus. Code C116137.

An electrocardiographic finding of a prolonged ST segment, resulting in an increased QT interval, without lengthening of the T wave duration; this may be observed in hypocalcemia. (CDISC) 